\title{
Friction wheel transmission of no-tillage corn planters
}

\author{
Jia Honglei ${ }^{1,2}$, Zhang Zhuo ${ }^{1,2}$, Chen Zhi ${ }^{3}$, Zheng Tiezhi', Zhao J iale ${ }^{1,2^{*}}$, Guo Mingzhuo ${ }^{1,2}$ \\ (1. College of Biological and Agricultural Engineering, Jilin University, Changchun 130025, China; \\ 2. Key Laboratory of Bionics Engineering, Ministry of Education, Jilin University, Changchun 130025, China; \\ 3. China National Machinery Industry Corporation, Beijing 100080, China; \\ 4. Jilin Agricultural Mechanization Management Center, Changchun 130022, China)
}

\begin{abstract}
To overcome the unfavorable factors of ground wheel-driven chain transmission when a no-tillage planter operates on straw mulching fields, a friction wheel transmission based on ground wheel transmission was designed in this research. The stability, i.e., the effects of friction wheel tyre pressure on stability of machine transmission was investigated via validation of main factors. The relationships among tyre pressure, deformation and load were determined via theoretical analysis. The tyre pressure extreme for transmission is $25.90 \mathrm{psi}$, the maximum pressure imposed on the friction wheel tyre is $14 \mathrm{kN}$, the maximum deformation of friction wheel is $8.7 \mathrm{~mm}$. The stabilities of friction wheel slip rate and seeding distance were investigated via field tests and alteration of friction wheel tyre pressure. After processing the test data, it can be found that the minimum tyre pressure for acquisition of friction wheel slip rate was 24.35 psi. After processing the data of seeding distance, it can be validated that the tyre pressure was kept unchanged following the optimal transmission effect of the transmission through the abrupt change of working speed, which further proved the feasibility of the new friction wheel transmission. The transmission of friction wheel can reduce $14.67 \%$ in variation coefficient of seed spacing at the speed of $5 \mathrm{~km} / \mathrm{h}$, and $16.22 \%$ at the speed of $8 \mathrm{~km} / \mathrm{h}$.
\end{abstract}

Keywords: no-tillage planter, corn, friction wheel transmission, slip rate, field test, variation coefficient, seeding distance DOI: $10.25165 /$ j.ijabe.20171004.2565

Citation: Jia H L, Zhang Z, Chen Z, Zheng T Z, Zhao J L, Guo M Z. Friction wheel transmission of no-tillage corn planters. Int J Agric \& Biol Eng, 2017; 10(4): 87-97.

\section{Introduction}

In recent years, conservation tillage technology has been extensively promoted in North and Northeast China $^{[1-3]}$. The core of the conservation tillage is the

\section{Received date: 2016-05-20 Accepted date: $2016-11-16$}

Biographies: Jia Honglei, $\mathrm{PhD}$, Professor, research interests: bionic intelligent agricultural machinery and conservation tillage technology, Email: jiahl@vip.163.com; Zhang Zhuo, PhD candidate, research interests: conservation tillage technology, Email: 497972939@qq.com; Chen Zhi, Professor, research interests: technology and equipment of corn harvester, Email: chenzhi@sinomach.com; Zheng Tiezhi, Professor, research interests: management of agricultural mechanization, Email: jlztz@126.com; Guo Mingzhuo, PhD, research interests: conservation tillage technology, Email: gmzgmzgmz@126.com.

*Corresponding author: Zhao Jiale, PhD, Lecturer, research interests: conservation tillage technique and agriculture mechanization design. Key Laboratory of Bionic Engineering (Ministry of Education), Jilin University, Changchun 130022, China. Tel: +86-18843165417, Email: zhaojiale0313@163.com. field surface crop residues (straw and root crop) mulching and no-till planting operation ${ }^{[4-6]}$. The no-till planters equipped with different functions in different regions in consideration of new surface environment ${ }^{[7,8]}$. For the existing no-till planter, land wheel drives the sowing and fertilizing parts through the chain ${ }^{[9,10]}$, and such mode can achieve good effect in North China area ${ }^{[11,12]}$. At present, common seed metering devices of no-till planter are also driven by chain drive in the northeastern region $^{[13-15]}$, such as $2 \mathrm{BJG}-12$ precision rototillingplanting machine developed by Heilongjiang Bayi Agricultural University and 2BZ-8 soybean precision seed spacing drill developed by Heilongjiang Agriculture and Secondary Product Processing Mechanization Research Institute ${ }^{[16,17]}$. Due to low temperature and susceptibility to drought in Northeast China, it is difficult for straws to decay ${ }^{[18-21]}$. No-till planter is easy to sliding on the surface of straw mulching during seeding 
in spring. Besides, straw mulching increased the vibration of chain transmission mechanism ${ }^{[22-24]}$. As a result, the sowing seed spacing variation coefficient increases, and the quality of planting operation is seriously affected ${ }^{[25,26]}$.

To solve the above problems, this study proposed the idea of replacing the chain transmission way through land wheel with the combined transmission mode of hydraulic technology, stacked friction wheel and transmission chain. The results showed that the tyre pressure and copying ability of friction wheel transmission mechanism could increase land wheel friction, reduce the slip rate of land wheel, and drop down the influence of straw mulching surface on the transmission mechanism, thus lower corn seed spacing variation coefficient, and improve the quality of seeding.

\section{Design of friction wheel transmission}

\subsection{Structural characteristics of friction wheel transmission}

To guarantee the switch between working and transport states for the routine traction-type no-tillage planters (commonly used in Northeast China), manufacturers installed a hydraulic device to control the lifting of the machine. During operation, when the working parts are set down to enter the working state, the seeding and fertilizing operations depend on the ground wheel transmission. The hydraulic device allows different working parts to lift off the ground to a certain height, but only depending on the ground surface movement and support from the ground wheel, the ground wheel can not be stabilized to transfer power to the working parts. The ground wheel serves as both the transmission wheel and the transport wheel, or namely, it switches between these two modes. At this moment, residues such as straw or weeds would pass diagonally though the ground wheel (or the press wheel if it is used as the transmission wheel), which interferes with the chain transmission. As shown in Figure 1, a 2BM-4A traction-typed no-tillage planter was made from a $2 \mathrm{BM}-4$ no-tillage planter by adding a small friction wheel, which, together with the ground wheel, hydraulic tank and their supports, constitutes a friction wheel transmission (Figure
2). The parameters of no-tillage planter are shown in Table 1 .

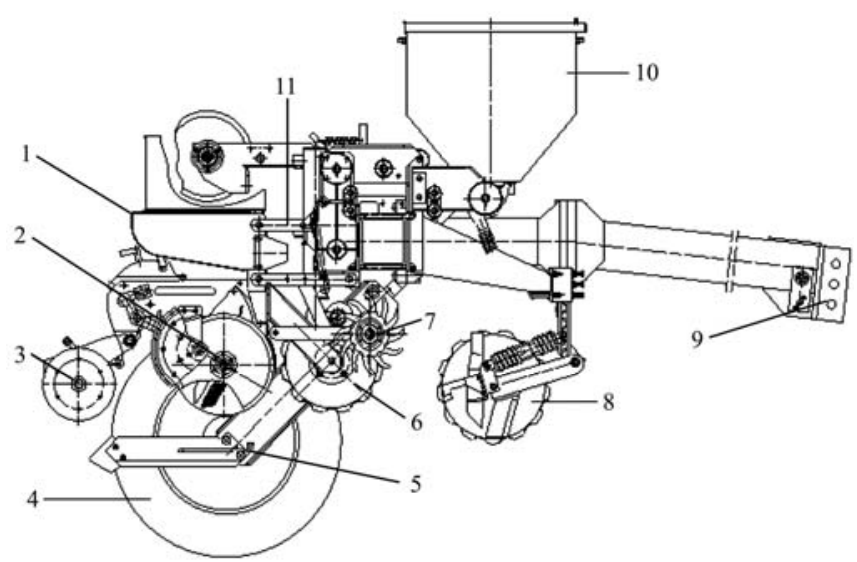

1. Seed case 2. Soil-covering depth wheel 3. Press wheel 4. Ground wheel 5. Ground wheel support 6. Double-disc sowing opener 7. Profiling claw-typed stubble (weed) cleaner 8. Notched disc fertilisation opener 9. Traction beam 10. Fertilisation case 11. Parallel four-bar profiling structure

Figure 1 Schematic diagram of 2BM-4A no-tillage planter

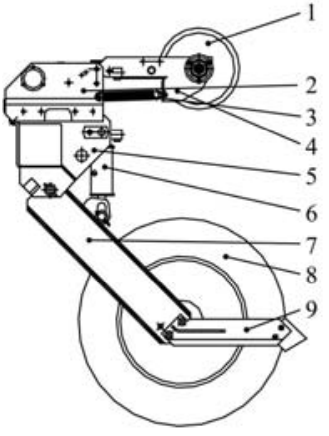

a. Main view

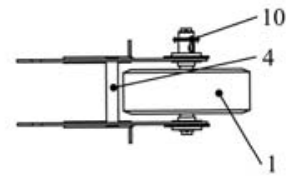

b. Vertical view

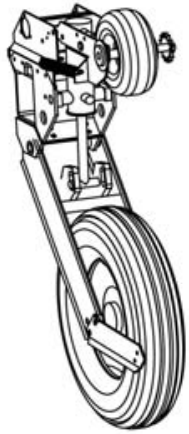

c. Axis view
1. Friction wheel 2. Intermediate connection frame 3. Tension spring

4. Transmission support 5 . Ground wheel junction plate 6 . Hydraulic cylinder 7. Ground wheel support 8 . Ground wheel 9. Scraper plate 10. Gear

Figure 2 Schematic diagram of friction wheel transmission

Table 1 Technical parameters of 2BM-4 no-till planter

\begin{tabular}{lc}
\hline \multicolumn{1}{c}{ Item } & Parameter \\
\hline Tractor horsepower/kW & $>74.8$ \\
Working width $/ \mathrm{m}$ & $2.6-2.8$ \\
Row spacing/cm & $60-70$ \\
Frame type & Trail-type \\
Crop & Corn \\
Seeder-metering device type & Cell drop \\
Opener type & Double-disc opener \\
Seeding depth $/ \mathrm{cm}$ & $2-8$ \\
Cleaning seed bed & Finger-type, anti-blocking residue-cleaner \\
Broken seed rate $/ \%$ & $<0.5$ \\
Fertiliser feeder type & External force feed \\
Fertiliser opener type & Notched disk \\
Fertiliser sowing amount $/ \mathrm{kg} \cdot \mathrm{hm}^{-2}$ & $150-600$ \\
Field speed $/ \mathrm{km} \cdot \mathrm{h}^{-1}$ & $4-6$ \\
Qualified seed spacing rate $/ \mathrm{cm}^{-1}$ & 21 \\
\hline
\end{tabular}

The ground wheel is directly hinged to the junction plate, so it can rotate around the hinging point. The 
friction wheel frame is hinged to the intermediate connection frame and installed with a limiting device, so that the friction wheel can rotate around the hinging point within a certain range, while the tension spring offers a pre-tightening force. The hydraulic cylinder is connected to the area between the ground wheel support and the ground wheel junction plate. One side of the friction wheel is installed with a sprocket, and via the sprocket connection between the chain and sowing/fertilizing parts, it transmits power outwards.

During operation, the machine would fall down through the contraction of the hydraulic cylinder, so the friction wheel is "set down" onto and completely contacts the ground wheel, and the machine moves forwards. Accordingly, the ground wheel rotates clockwise on ground, and through friction it drives the friction wheel to rotate counter-clockwise (as shown in Figure 3). The rotation of the friction wheel drives the coaxial chain wheel rotating, and finally, transmits the power to the seed-metering device and the fertiliser device. In this way, the off-surface height of the centre of the active sprocket is the sum of the ground wheel diameter and friction wheel radius. Therefore, the impact from ground mulching is negligible. In the turn-row and transport state, the piston bar of the hydraulic cylinder is controlled to elevate the machine, so the ground wheel (6.5-20 bias tyre) and the friction wheel $(13 \times 5.00-6$ rubber tyre) are separated, while the power of the working parts is cut off.

\section{Simulation and analysis of transmission}

\subsection{Rolling friction between tyres}

To reduce the rolling resistance for the machine, an attempt was made to decrease the dynamic deformation of the ground wheel and consider it rolling motion to be circular (assuming that the two tyres are treadless). The ground wheel rotates with the advancing of the machine and drives the friction wheel rotating to realize power transfer. At this moment, the action force (resultant force) of the ground wheel on the friction wheel is imposed on an "arc" at the right-hand side of the two-wheel contact site (Figure 3), where $N$ (rolling friction) acts in a direction normal to the contact arc:

$$
\vec{N}=\overrightarrow{N_{y}}+\overrightarrow{N_{x}}
$$

where, $N$ is the force of friction wheel, $\mathrm{N} ; N_{x}$ is the horizontal force of friction wheel, $\mathrm{N} ; N_{y}$ is the vertical force of friction wheel, $\mathrm{N}$.

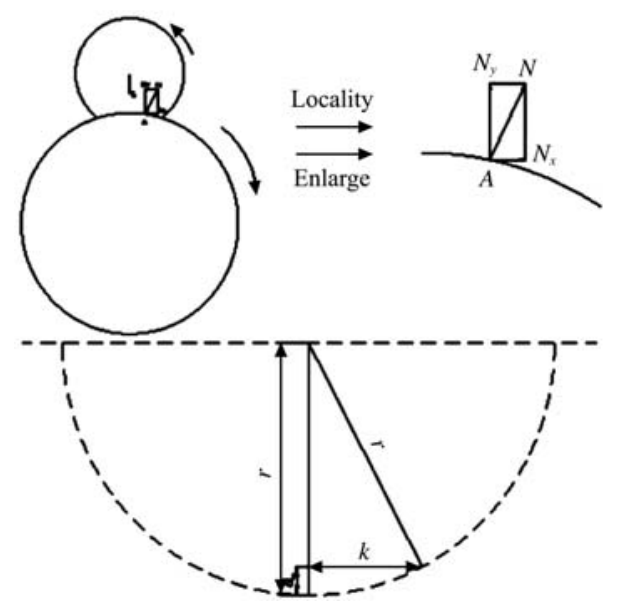

Figure 3 Force and deformation diagram of friction wheel

In fact, $N_{x}$ is extremely small and it can be stated that $N_{y}$ is equal to the force $G$ imposed vertically downwards on the friction wheel by the machine. In this way, the two forces $G$ and $N_{y}$ borne by the friction wheel are equal, directionally opposite, and not superimposed; and is thus a couple, which makes it roll on the ground wheel.

Let the horizontal distance between $N_{y}$ and $G$ (namely the lever arm of friction $N$ to the wheel core) be $K$, then the couple is:

$$
M=K N_{y}=K G
$$

However, since two tyres interact in practice, the tyre deformation arcs are very small, so it can be inferred that the deformation of the friction wheel tyre is approximately the difference between the friction wheel radius $r$, and the distance from the point of action of the force to the core of the friction wheel (the driven wheel):

$$
\Delta L=r-\sqrt{r_{2}-k^{2}}
$$

According to the known tyre load-deformation curve, the load-deformation relationship at different tyre inflation pressures can be expressed in a polynomial as follows:

$$
W=k_{1} \Delta L+k_{2} \Delta L^{2}+k_{3} \Delta L^{3}
$$

where, $W$ is the tyre load, $\mathrm{N} ; \Delta L$ is the radial deformation, $\mathrm{m}$; and $K_{i}(i=1,2,3)$ is the coefficient of elasticity, $\mathrm{N} / \mathrm{m}$.

In the above load-deformation equation, the effect of charging pressure is hidden in $K_{i}(i=1,2,3)$, which can be expressed as follows: 


$$
\begin{aligned}
W= & a_{1} \Delta L+a_{2} p_{1}+a_{3} \Delta L^{2}+a_{1} p_{1} \Delta L+a_{4} p_{1} \Delta L+ \\
& a_{5} p_{1}^{2}+a_{6} \Delta L^{3}+a_{7} \Delta L^{2} p_{1}+a_{8} \Delta L_{1}^{2}+a_{9} \Delta L_{1}^{3}
\end{aligned}
$$

where, $a_{i}(i=1,2, \ldots, 9)$ is the empirical coefficient to be determined, and $p_{i}$ is the air pressure inside the tyre, $\mathrm{Pa}$.

Then $a_{i}(i=1,2, \ldots, 9)$ is computed via multiple stepwise regression. Through regression and computation, the insignificant variables are removed, so the relationships between tyre load, air charging pressure, and tyre deformation can be obtained:

$$
W=a_{1} \Delta L+a_{4} p_{1} \Delta L+a_{7} \Delta L^{2} p_{1}
$$

From the above equations, the flowing equation can be obtained:

$$
\left[\begin{array}{ccc}
\Delta L_{1} & p_{1} \Delta L_{1} & \Delta L_{1}^{2} p_{1} \\
\Delta L_{2} & p_{2} \Delta L_{2} & \Delta L_{2}^{2} p_{2} \\
\Delta L_{3} & p_{3} \Delta L_{3} & \Delta L_{3}^{2} p_{3}
\end{array}\right]\left[\begin{array}{l}
a_{1} \\
a_{4} \\
a_{7}
\end{array}\right]=\left[\begin{array}{l}
W_{1} \\
W_{2} \\
W_{3}
\end{array}\right]
$$

As for the $13 \times 5.00-6$ tyre, the deformation corresponding to a pressure under a given load is known. Thus, for $a_{i}$, if the load and the measured deformation in practice are provided, the corresponding tyre pressure can be calculated. The values of $a_{1}, a_{2}$ and $a_{3}$ of the tyre are listed in Table 2.

Table 2 Values of $a_{1}, a_{4}$ and $a_{7}$

\begin{tabular}{cccc}
\hline Wheel & $a_{1} / \mathrm{kN} \cdot \mathrm{m}^{-1}$ & $a_{4} / \mathrm{m}$ & $a_{7}$ (dimensionless) \\
\hline $13 \times 5.00-6$ & 21.473 & 5.821 & 10.375 \\
\hline
\end{tabular}

By measurement, the maximum resisting moment of seeding and fertilising parts on the double-wheel transmission machine is $122 \mathrm{~N} \cdot \mathrm{m}$, while the force imposed on the friction wheel tyre is $14 \mathrm{kN}$. Substituting these data into the relevant equations, the theoretical minimum tyre deformation is:

$$
\Delta L_{\text {theory }}=0.0087 \mathrm{~m}
$$

In actual operation, due to ground level fluctuations, the friction wheel transmission bears part of the weight of the machine. Thus, when the machine passes through different turning points on fluctuating ground, the friction wheel would bounce inertially. Let the amount of bounce be $\Delta L_{0}$, which can be decomposed into the upward bounce $\Delta L_{\text {up }}$ and downward bounce $\Delta L_{\text {down }}$. In operation, the deformation of the friction wheel should not be less than $\Delta L_{\text {theory, so the real tyre }}$ deformation is:

$$
\Delta L_{\text {real }}=\Delta L_{\text {theory }}+\Delta L_{\text {down }}
$$

\subsection{Simulation and analysis of transmission}

\subsubsection{Simulation and analysis in ADAMS}

Whether the simulation analysis is accuracy or not is mainly decided by the adoption of the correct modelling approach and appropriate parameter setting. This study modelled in strict accordance with the physical structure and added a contact restraint. The accuracy of modelling is guaranteed by analysing the model weight. Then the selection of different parameters was examined. The main parameters include: the drive parameters of the complete machine model, the material setting of different parts, the rolling friction coefficient, and the contact setting.

Since the targets of simulation analysis are the ground wheel and the friction wheel, the motions of other soil-contact parts during the simulations were ignored; however, the two-tyre interaction is very complex, so this research only validated its trail at two wheel shafts under the action of traction, but this trail changes continuously as the small-wheel bounces on the ground. During the analysis, the whole model was driven forwards by a tractor, and the motion of the friction wheel transmission was analysed. Therefore, it was assumed that the contact collisions between the transmission tyres, and between the tyres and the ground. The transmission can roll under the drive of the ground-wheel/ ground friction and the ground wheel/friction wheel friction. The parameter affecting the contact friction is the friction factor, which is a key factor affecting the tyre skidding on the ground, the rotation of the friction tyres, and also the bounce of the friction wheel tyre. Thus, appropriate setting of material properties of different parts is pivotal.

The surface material of tyres was synthetic rubber, carbon black, bead wire, etc., but we mainly simulated the profiling of the transmission to the ground conditions, and investigated the amount of bounce of the friction wheel induced only by terrain changes, so it was assumed that the material of the friction wheel tyres was rigid. Moreover, the ground wheel tyre was made of tread rubber, with density $\rho=1.2 \times 10^{3} \mathrm{~kg} / \mathrm{m}^{3}$, Poisson's ratio 0.3 , elastic modulus $E=9.8 \times 10^{6} \mathrm{~Pa}$, and the glide friction coefficient between steel and hard rubber is 0.36 . In the model, to ensure the model weight characteristics are 
consistent with the prototype, the team determined the parts of rigid materials to be of density $\rho=7.8 \times 10^{3} \mathrm{~kg} / \mathrm{m}^{3}$, Poisson's ratio $=0.3$, and elastic modulus $E=2 \times 10^{11} \mathrm{~Pa}$.

The material properties of the fluctuating ground are also key factors affecting the simulation results. As reported, triaxial tests show that soil elastic modulus $E$ is $2.25 \times 10^{6} \mathrm{~Pa}$ at a water content of $12 \%$ and $1.18 \times 10^{6} \mathrm{~Pa}$ at a water content $22 \%$; to guarantee the same soil content, we used simulated soils with $E=1.18 \times 10^{6} \mathrm{~Pa}$ and Poisson's ratio between 0.4 and $0.5^{[27]}$.

Given that the slide static friction coefficient of new tyres is 0.50 , and that of worn tyres is 0.40 , and given the tyre wear during operation, the friction coefficient upon contact was set to 0.4 , and the dynamic friction coefficient was set slightly smaller than 0.4 (Figure 4).

\begin{tabular}{|c|c|c|c|}
\hline | F Force Display & Red & $\Xi$ & \\
\hline Normal Force & Impact & & 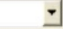 \\
\hline Stiffness & 200 & & \\
\hline Force Exponent & 2 & & \\
\hline Damping & 0.2 & & \\
\hline Penetration Depth & 0.1 & & \\
\hline \multicolumn{4}{|l|}{ I Augmented Lagrangian } \\
\hline Friction Force & Coulomb & & 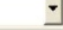 \\
\hline Coulomb Friction & On & & $\boldsymbol{\Psi}$ \\
\hline Static Coefficient & $0.4 \mid$ & & \\
\hline Dynamic Coefficient & 0.36 & & \\
\hline Stiction Transition Vel. & 100.0 & & \\
\hline Friction Transition Vel. & 1000.0 & & \\
\hline & $\underline{\mathrm{O}} \mathrm{K}$ & Apply & Close \\
\hline
\end{tabular}

\begin{tabular}{|c|c|c|c|}
\hline \multirow{2}{*}{$\begin{array}{l}\text { F Force Display } \\
\text { Normal Force }\end{array}$} & \multicolumn{3}{|l|}{ Red } \\
\hline & Impact & & $\dot{\theta}$ \\
\hline Stiffness & $1.0 E+005$ & & \\
\hline Force Exponent & 1.5 & & \\
\hline Damping & 10 & & \\
\hline Penetration Depth & 0.1 & & \\
\hline \multicolumn{4}{|l|}{$\Gamma$ Augmented Lagrangian } \\
\hline Friction Force & Coulomb & & 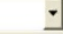 \\
\hline Coulomb Friction & On & & 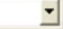 \\
\hline Static Coefficient & 0.35 & & \\
\hline Dynamic Coefficient & 0.32 & & \\
\hline Stiction Transition Vel. & 100.0 & & \\
\hline Friction Transition Vel. & 1000.0 & & \\
\hline & $\underline{\mathrm{OK}}$ & Apply & Close \\
\hline
\end{tabular}

Figure 4 Schematic diagram of contact parameters

Since the simulation target was a two-wheel transmission, the weights of other ignored parts for a no-tillage planter should be loaded to the transmission. In real operation, the self-weight of the whole machine is supported by the arm of the small wheel, so during simulation, the weight of the whole no-tillage planter is used to replace that of the transmission.

After addition of drive and restraints, the model is as shown in Figures 5 and 6. Before simulation, the model had to be tested to eliminate errors. The test contents should include two parts: 1) Model self-test: testing whether, or not, there is inappropriate connection/restraint, whether there is a restraint-less/weight-less component, and whether the number of modelled degrees of freedom is correct. 2) Analysis of assembly: testing whether, or not, the restraints in the model file are completed, and whether they are breached, or ill-defined ${ }^{[28]}$.

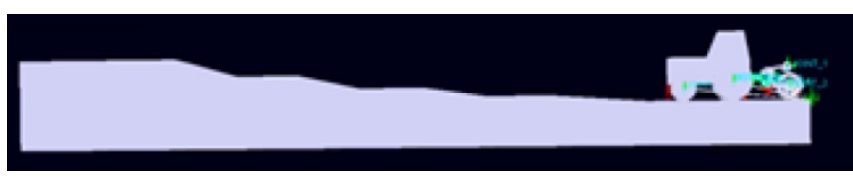

Figure 5 Simulation model of uphill motion

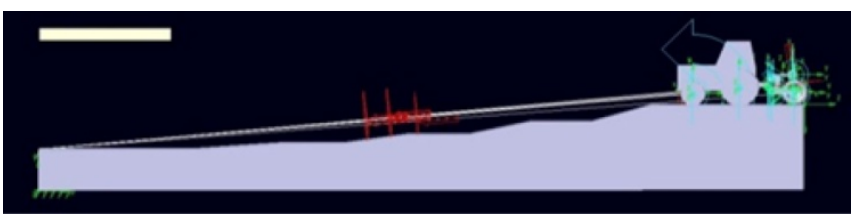

Figure 6 Simulation model of downhill motion

\subsubsection{Simulation and analysis of movement in ADAMS}

Figures 7 and 8 show the shaft centre trails of the ground wheel and the transmission wheel when the model was advancing at its normal working speed.

As shown in Figures 7 and 8, when the two-wheel transmission is simulated in ADAMS, the tyre shaft centre displacement trails of the ground wheel and the small transmission wheel are both smooth. No excessively large bounce occurred despite the fluctuating ground, and according to the shapes of the two curves, the profiling effects of the ground wheel and the friction wheel are good, suggesting good results. Moreover, the trends in the displacement curves of the two tyres are similar. Thus, it can be concluded that the relative profiling effects of the ground wheel and the friction wheel are good.

Figures 9 and 10 show the displacement differential curves at the ground wheel and the friction wheel shafts when the friction wheel transmission is moving uphill and downhill, respectively, in these simulations. During uphill operations, the displacement differential curves of the two tyres can be approximated as a horizontal straight line. It is indicated that, when the ground wheel and the friction wheel are working along with ground surface changes, the relative longitudinal displacements are approximately unchanged. Thus, it is also suggested that the hydraulic control up-down friction wheel transmission designed here provides reliable transmission. As shown by the displacement differential curves of the two tyres during the simulation of uphill surfaces, when the no-tillage planter works on slopes of $+4^{\circ},+8^{\circ},+12^{\circ}$ and $+16^{\circ}$, the two tyres of the friction wheel transmission yield a displacement differential of $9.4 \mathrm{~mm}$ due to inertia, including an upper differential $c$ of $3.9 \mathrm{~mm}$ and a lower differential of $5.5 \mathrm{~mm}$. Similarly, the displacement 
differential curves of downhill operation show that, when the friction wheel transmission works on slopes of $-4^{\circ}$, $-8^{\circ},-12^{\circ}$ and $-16^{\circ}$, the displacement differential due to inertia between the two tyres is $10.5 \mathrm{~mm}$, including an upper differential of $4.2 \mathrm{~mm}$ and a lower differential of $6.3 \mathrm{~mm}$. These data show that the shaft centre longitudinal displacement differential of the two tyres during downhill working is larger than that seen when moving uphill. This is because, as the machine advances uphill, the buffering effect of the tyre rubber decreases the change, but when the machine moves downhill, the buffer effect is insignificant, so the change is relatively large. As shown in Figure 11, the points, where the shaft centre longitudinal distance between the ground wheel and friction wheel changes, mostly appear when the tyres pass through sloping fields.

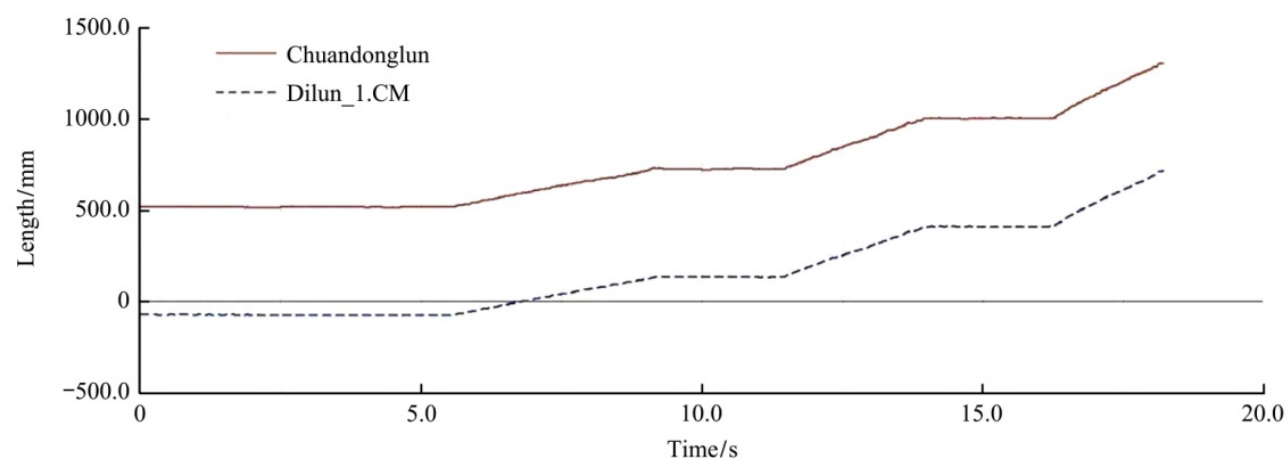

Figure 7 Shaft centre trail of uphill motion

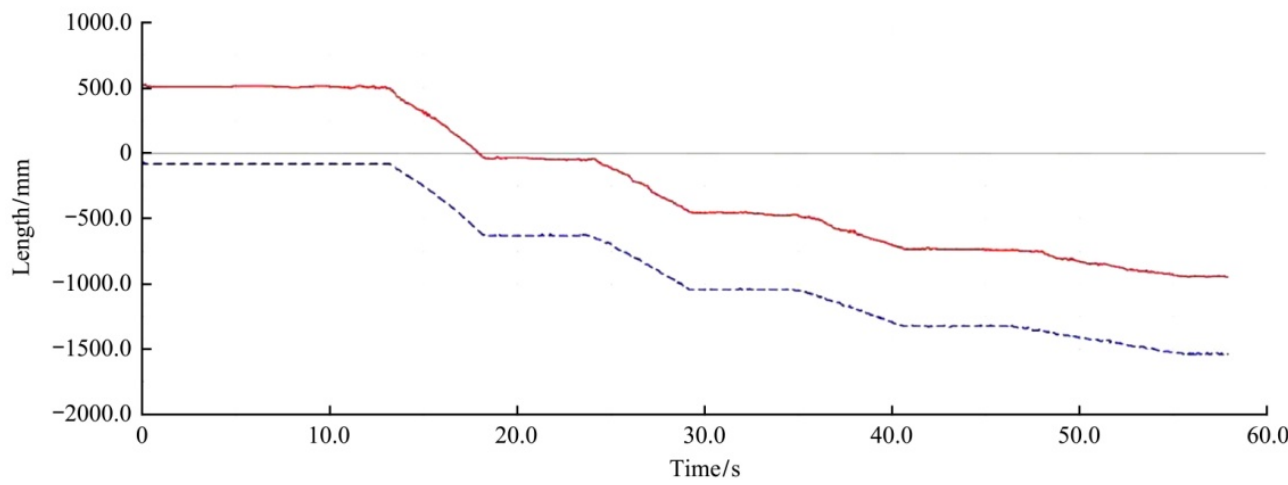

Figure 8 Shaft centre trail of downhill motion

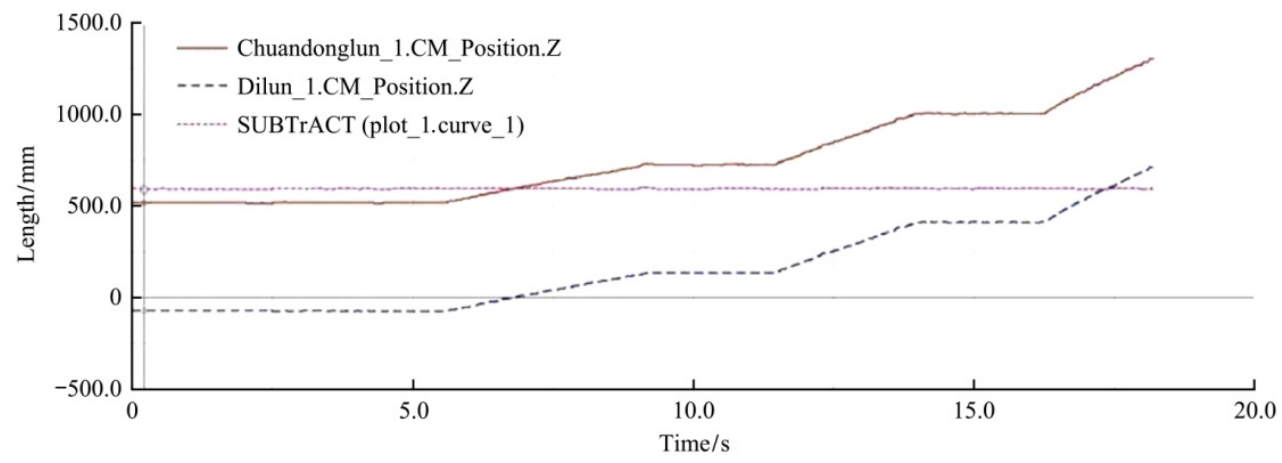

Figure 9 Shaft centre displacement and displacement differential curve of uphill motion

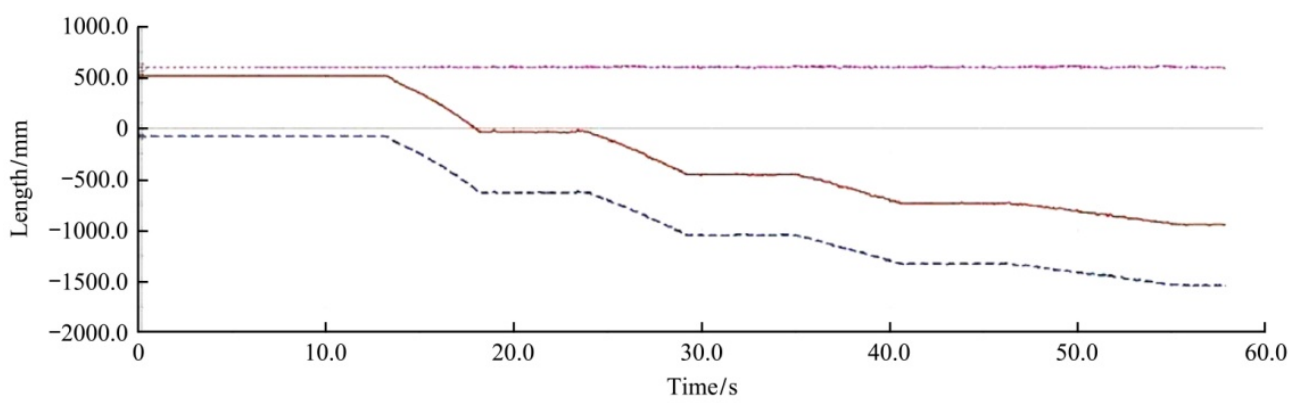

Figure 10 Shaft centre displacement and displacement differential curve of downhill motion 


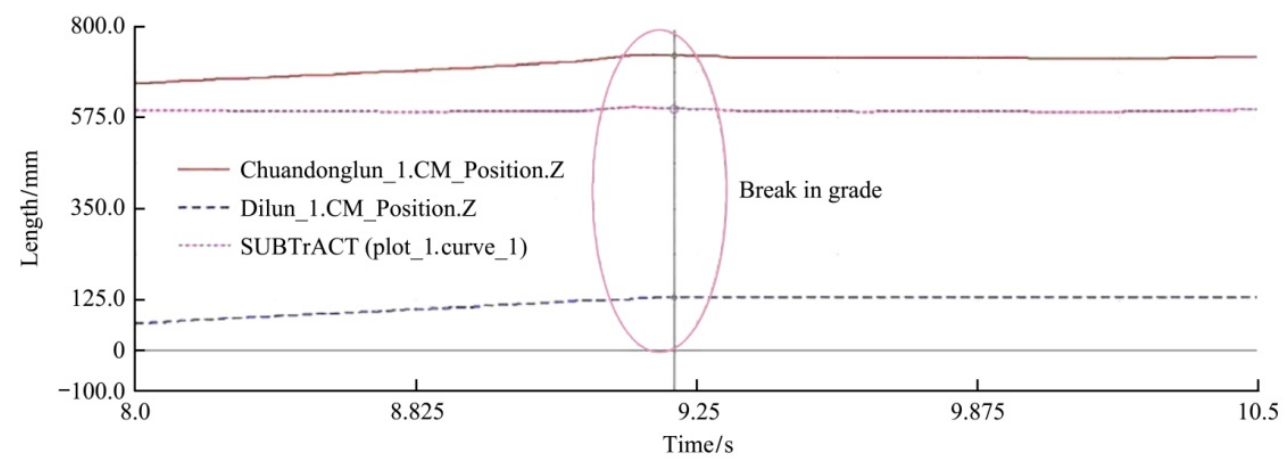

Figure 11 Schematic diagram of slope angle effect

In other words, during field operations, according to the slope characteristics of cultivated land in Northeast China, the friction wheel transmission, along with the slope-variable ground, mean that the distance between the ground wheel and friction wheel will longitudinally deviate to the largest extent by $10.5 \mathrm{~mm}$, including an upper differential of $4.2 \mathrm{~mm}$ and a lower differential of $6.3 \mathrm{~mm}$. As discussed in Section 2, within a certain range, the transmission effect is better with a larger tyre deformation. Thus, during the design process, we pay special attention to the differential of shaft centre displacements of the two tyres. Using the results as feedback, the tyre deformation differentials of the friction wheel transmission from the theoretical computations would be substituted back into the equations to obtain the data best-approximating reality.

From Equation (9):

$$
\Delta L_{\text {real }}=\Delta L_{\text {theory }}+\Delta L_{\text {down }}=0.0129 \mathrm{~m}
$$

From Equation (6):

$$
P=\frac{W-a_{1} \Delta L}{a_{4} \Delta L+a_{7} \Delta L^{2}}=178.6 \mathrm{kPa}
$$

The tyre deformation substituted to the equations is the sum of the minimum deformation theoretically needed to drive the load of $122 \mathrm{~N} \cdot \mathrm{m}$ torque, the load imposed on the friction wheel tyre is $14 \mathrm{kN}$, the deformation of friction wheel is $8.7 \mathrm{~mm}$, and the maximum bounce of the friction wheel when the transmission machine is running on different ground surfaces. In this way, the pressure determined from the equations is the real maximum air charging tyre pressure of the friction wheel (178.6 kPa here).

\section{Transmission effect and field tests}

Field tests were undertaken to test the slip of hydraulic up-down friction wheel transmission under different tyre pressures and to measure its effect on the qualified rate of seeding distance.

\subsection{Materials and methods}

The field tests were conducted in the test field at Jilin Academy of Agricultural Machinery on May 16, 2013. The soil cone index was measured with an SZ-3 soil cone tester; soil water content was detected with a T-300 soil moisture temperature tester (the testing points were selected from the parallelogram diagonal equidistant method, each using five points). The measurements of average soil cone index are: 0.77 (50 $\mathrm{mm}$ in depth), 0.93 (100 $\mathrm{mm}$ in depth), and 1.20 (150 $\mathrm{mm}$ in depth). The soil volumetric moisture contents are: $12.33 \%(50 \mathrm{~mm}$ in depth), $14.12 \%$ (100 mm in depth) and 16.62\% (150 mm in depth). The soil physical and chemical properties are listed in Table 3. This study previously measured the fluctuations within $20 \mathrm{~m}$ between two ridges (Table 4 and Figure 12$)^{[29]}$. The planting crop is corn, at a seed spacing of $21 \mathrm{~cm}$.

A John Deere 850 tractor was used in the field tests. The test prototype and the test field are shown in Figure 13. The key parameters of the John Deere 850 are listed in Table 5.

Table 3 Soil physical and chemical properties at depths of 0-100 $\mathrm{mm}$ in the test field

\begin{tabular}{lc}
\hline \multicolumn{1}{c}{ Property } & Value \\
\hline Cone index $/ \mathrm{MPa}$ & 0.913 \\
Volume density $/ \mathrm{g} \cdot \mathrm{cm}^{-3}$ & 1.237 \\
Moisture content $/ \%$ d.b. & 21.2 \\
Soil temperature $/{ }^{\circ} \mathrm{C}$ & 13.2 \\
$\mathrm{pH}$ & 7.08 \\
Organic matter $/ \%$ & 3.78 \\
Total nitrogen $/ \%$ & 0.13 \\
Available potassium $\left(\mathrm{K}_{2} \mathrm{O}\right) / \mathrm{mg}^{-3} \mathrm{~kg}^{-1}$ & 173.2 \\
Available phosphorus $\left(\mathrm{P}_{2} \mathrm{O}_{5}\right) / \mathrm{mg}^{-} \mathrm{kg}^{-1}$ & 16.5 \\
Average annual rainfall $/ \mathrm{mm}$ & $450-550$ \\
\hline
\end{tabular}


Table 4 Distances to test points and datum line in the field plot

\begin{tabular}{|c|c|c|c|c|c|c|c|c|c|c|c|}
\hline \multirow{2}{*}{ Field plot/mm } & \multicolumn{11}{|c|}{ Depth/m } \\
\hline & 0 & 2 & 4 & 6 & 8 & 10 & 12 & 14 & 16 & 18 & 20 \\
\hline 1 & 200 & 158 & 140 & 188 & 126 & 173 & 210 & 170 & 158 & 255 & 240 \\
\hline 2 & 200 & 201 & 145 & 178 & 165 & 163 & 210 & 190 & 155 & 220 & 208 \\
\hline Mean & 200 & 179.5 & 142.5 & 183 & 145.5 & 168 & 210 & 180 & 156.5 & 237.5 & 224 \\
\hline
\end{tabular}

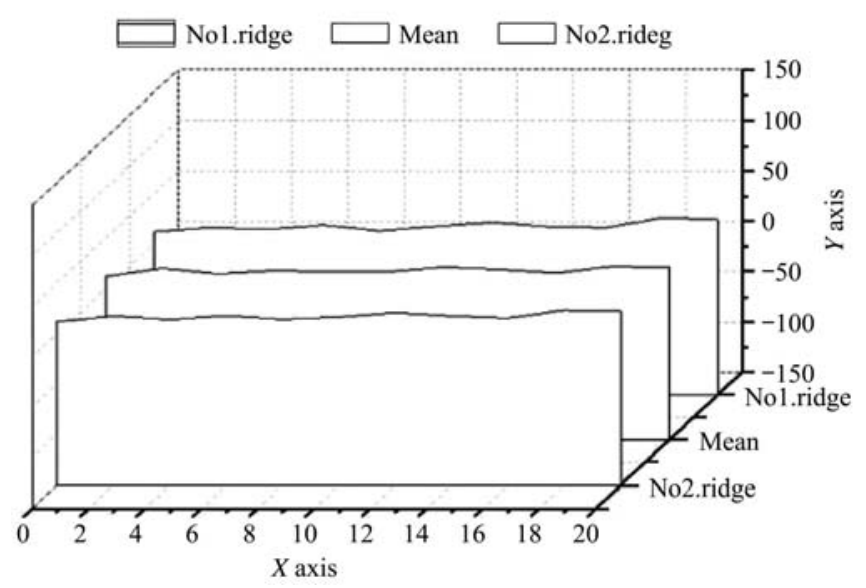

Figure 12 Trend in rolling grade across the field plot
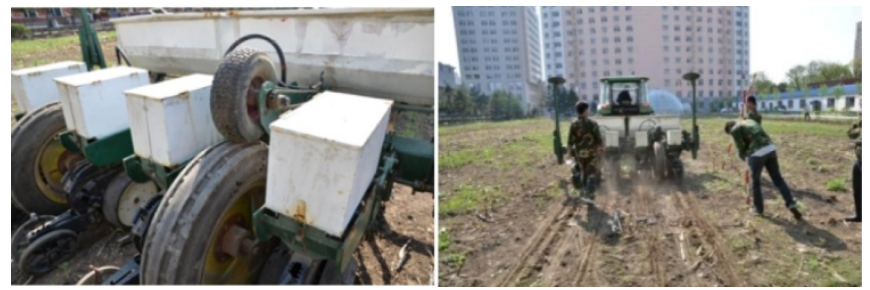

Figure 13 Experimental prototype and experimental field

Table 5 Parameters of the John Deere 850

\begin{tabular}{lc}
\hline Engine power/hp & 85 \\
Rated engine speed $/ \mathrm{r} \cdot \mathrm{min}^{-1}$ & 2300 \\
Engine type & $\begin{array}{c}\text { Vertical, direct injection, water-cooled, } \\
\text { four-stroke diesel engine }\end{array}$ \\
Air intake type & Inter-cooling \\
Cylinder bore and stroke/mm & $106.5 \times 127$ \\
Fuel consumption $/ \mathrm{g} \cdot(\mathrm{kW} \cdot \mathrm{h})^{-1}$ & $\leq 242$ \\
Lubrication system & Force-feed lubrication \\
Fuel system & High-pressure common rail \\
PTO speed $/ \mathrm{r} \cdot \mathrm{min}^{-1}$ & Standard PTO 830, optional PTO 650/830 \\
Hydraulic system & open-centre, partially separated units \\
& partially separated units: $19.5-20.5 ;$ \\
Rated hydraulic pressure $/ \mathrm{kPa}$ & separated units: $17-18.5$ \\
Pump rated output $/ \mathrm{L} \cdot \mathrm{min}{ }^{-1}$ & $\geq 37$ \\
Min radius of turning circle $/ \mathrm{m}$ & 4.3 \\
Wheelbase/mm & 2200 (2 WD dimensions) \\
\hline
\end{tabular}

\subsection{Test methods}

This study set two machine operating modes: advancing speed at $5 \mathrm{~km} / \mathrm{h}$ and $8 \mathrm{~km} / \mathrm{h}$. Under each mode, the friction wheel tyre pressures were set to $30 \mathrm{psi}$, 25 psi, 20 psi, 15 psi and 10 psi. In each condition, this study measured the relative ground slip rate between two wheels and the qualified rate of seeding distance.

\section{(1) Measurement of slip rate}

Slip rate is defined as the proportion of slip components during the wheel rolling process. Within the zone when the ground wheel walks 10 circles, this study measured the real distance when the ground wheel rolls 10 circles, and recorded the number of rotations of the friction wheel. The theoretical distances (or as taped) and the friction wheel travel could be independently determined from the number of rotations. In this way, the slip rates of the ground wheel and the friction wheel relative to the ground can be determined ${ }^{[30]}$.

(2) Detection of qualified rate of seeding distance

A seed in the middle of the testing area was selected as the starting point (i.e., coordinate origin). Then 10 other seeds in succession were selected and the distance of each seed from the previous seed was determined, which was used to compute the seeding distance ${ }^{[31]}$.

\subsection{Results and analysis}

\subsubsection{Results}

The measurements and processed data of tyre slip rate are listed in Table 6 , the measurements of seeding distance are listed in Table 7, and the processed seeding uniformity data are listed in Table 8 .

Table 6 Value of tyre slip rate

\begin{tabular}{cccccc}
\hline Mode & P/psi & $\begin{array}{c}\text { Rotation number } \\
\text { of ground wheel }\end{array}$ & $\begin{array}{c}\text { Rotation number } \\
\text { of small wheel }\end{array}$ & $\begin{array}{c}\text { Speed } \\
/ \mathrm{km} \cdot \mathrm{h}^{-1}\end{array}$ & $\begin{array}{c}\text { Real } \\
\text { distance/cm }\end{array}$ \\
\hline & 30 & 10 & 25.1 & 5 & 39.41 \\
1 & 25 & 10 & 28.2 & 5 & 39.50 \\
& 20 & 10 & 27.2 & 5 & 40.12 \\
& 15 & 10 & 25.1 & 5 & 39.33 \\
& 10 & 10 & 22.1 & 5 & 40.02 \\
\hline & 30 & 10 & 23.2 & 8 & 39.78 \\
& 25 & 10 & 27.0 & 8 & 39.25 \\
& 20 & 10 & 25.4 & 8 & 39.91 \\
& 15 & 10 & 23.0 & 8 & 39.90 \\
& 10 & 10 & 21.3 & 8 & 40.05 \\
\hline
\end{tabular}


Table 7 Measurement of seeding effect

\begin{tabular}{|c|c|c|c|c|c|c|c|c|c|c|c|}
\hline \multirow{2}{*}{ Mode } & \multirow{2}{*}{$P /$ psi } & \multicolumn{10}{|c|}{ Ten consecutive seeding distances/cm } \\
\hline & & 1 & 2 & 3 & 4 & 5 & 6 & 7 & 8 & 9 & 10 \\
\hline \multirow{5}{*}{1} & 30 & 22.6 & 24.3 & 23.5 & 22.1 & 23.6 & 22.7 & 24.6 & 23.4 & 23.1 & 26.4 \\
\hline & 25 & 21.4 & 22.8 & 21.8 & 21.3 & 22.5 & 22.6 & 22.1 & 21.8 & 20.6 & 21.7 \\
\hline & 20 & 21.6 & 22.3 & 21.8 & 24.2 & 24.7 & 24.2 & 22.1 & 22.4 & 22.3 & 20.8 \\
\hline & 15 & 22.7 & 23.4 & 25.6 & 24.9 & 26.7 & 25.3 & 25.1 & 24.6 & 24.5 & 26.2 \\
\hline & 10 & 24.5 & 26.7 & 28.2 & 28.6 & 27.4 & 30.6 & 27.4 & 26.6 & 38.2 & 29.4 \\
\hline \multirow{5}{*}{2} & 30 & 22.2 & 24.3 & 23.5 & 26.6 & 26.2 & 24.2 & 24.6 & 25.4 & 25.2 & 27 \\
\hline & 25 & 22.6 & 21.4 & 22.8 & 22.4 & 21.6 & 23.4 & 22.1 & 23.8 & 23.6 & 23.2 \\
\hline & 20 & 23.4 & 22.8 & 27.1 & 26.4 & 23.4 & 23.5 & 24.1 & 23.3 & 24.6 & 22.8 \\
\hline & 15 & 23.4 & 24.6 & 23.8 & 24.7 & 31.5 & 28.6 & 27.7 & 29.4 & 32.4 & 26.4 \\
\hline & 10 & 28.6 & 27.5 & 35.4 & 29.1 & 24.6 & 24.8 & 28.6 & 30.7 & 32.5 & 26.8 \\
\hline
\end{tabular}

Table 8 Uniformity of the seed distribution

\begin{tabular}{|c|c|c|c|c|c|}
\hline Mode & Tyre pressure/psi & Mean of samples/cm & Variance of samples & Standard deviation of samples & Variation coefficient $/ \%$ \\
\hline \multirow{5}{*}{1} & 30 & 23.23 & 6.0650 & 2.4627 & 10.60 \\
\hline & 25 & 21.66 & 4.1144 & 2.0284 & 9.36 \\
\hline & 20 & 22.64 & 14.5620 & 3.8160 & 16.86 \\
\hline & 15 & 24.90 & 11.9600 & 3.4583 & 13.89 \\
\hline & 10 & 27.76 & 25.2040 & 5.0206 & 18.09 \\
\hline \multirow{4}{*}{2} & 25 & 22.69 & 6.1290 & 2.4757 & 10.91 \\
\hline & 20 & 24.14 & 19.8840 & 4.4591 & 16.62 \\
\hline & 15 & 27.25 & 92.2050 & 9.6023 & 35.24 \\
\hline & 10 & 28.86 & 100.3240 & 10.0162 & 34.71 \\
\hline
\end{tabular}

\subsubsection{Analysis of results}

(1) Relationship between friction wheel tyre pressure and slip rate

Curves were fitted on MATLAB ${ }^{\mathrm{TM}}$ : with five known points, the curve was fitted with a cubic polynomial through approximate interpolation. As shown in Figure $14(5 \mathrm{~km} / \mathrm{h}$ and $8 \mathrm{~km} / \mathrm{h})$, the broken line is composed from the $[P, \delta]$ data, while the real line is composed of approximate data from all points fitted from the polynomial. It is clear that the curve fitting effect is reasonable.

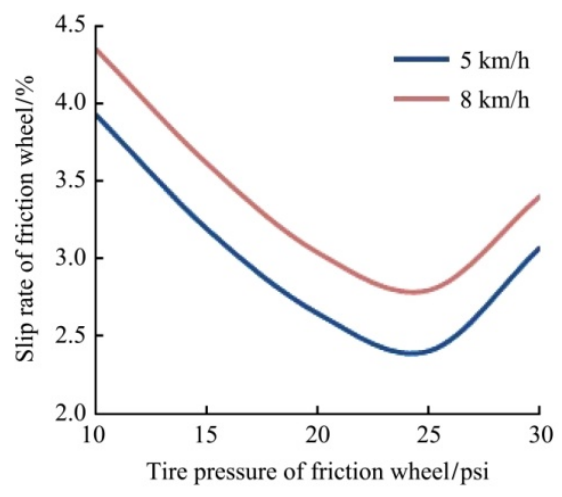

Figure 14 Curves of slip rate-tyre pressure under two operating modes
The polynomial was resolved on MATLAB ${ }^{\mathrm{TM}}$, to get $y_{\min }=2.28 \%$, when $x=24.3450$, indicating that the optimal transmission effect (when the slip rate was lowest) of the friction wheel transmission corresponds to the friction wheel tyre pressure $24.345 \mathrm{psi}$, or $167.859 \mathrm{kPa}$.

If the working speed is increased ( $8 \mathrm{~km} / \mathrm{h}$, Figure 14$)$, the transmission effect of friction wheel transmission would be affected to some extent; as the working speed of the machine is increased, the corresponding tyre pressure required to match the slip rate would be improved slightly. Nevertheless, the overall trend remained practically unchanged, while the positions of the extremum points on the curve did change (i.e., the optimal tyre pressure was constant).

(2) Variable coefficient of seeding distance

Using the data in Tables 7 and 8, the variation coefficients of seeding distance were plotted (Figure 15).

Under the same operating mode, the coefficient of variation is very low at a tyre pressure of $25 \mathrm{psi}$, but it increases at values above and below 25 psi. Results suggest that the transmission effect of the friction wheel 
transmission were acceptable at the appropriate tyre pressure, but the transmission was destabilised when the tyre pressure deviated from optimal. By comparing the coefficients of variation between operating modes 1 $(5 \mathrm{~km} / \mathrm{h})$ and $2(8 \mathrm{~km} / \mathrm{h})$, it can be found that the increase in working speed would lead to a reduction in transmission efficacy.

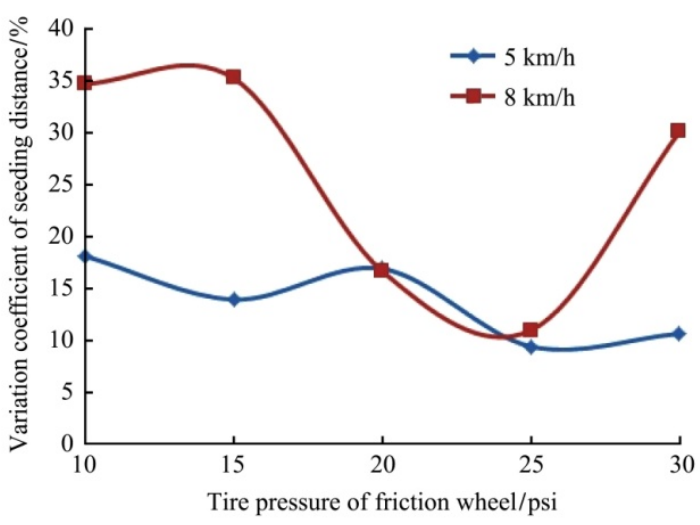

Figure 15 Variation coefficient $v s$ tyre pressure

The test of no-tillage seeding in different operating conditions was carried on with the use of a 2BM-4 no-till planter (the land wheel drives the chain wheel) and a 2BM-4A no-till planter (driven by a friction wheel, with a tyre pressure of $25 \mathrm{psi}$ ), respectively: the results are summarised in Table 9. Transmission via the friction wheel saw a $14.67 \%$ reduction in variation coefficient of seed spacing at a speed of $5 \mathrm{~km} / \mathrm{h}$ and a $16.22 \%$ reduction therein at $8 \mathrm{~km} / \mathrm{h}$.

Table 9 Results of contrast test

\begin{tabular}{ccccc}
\hline $\begin{array}{c}\text { Speed } \\
/ \mathrm{km} \cdot \mathrm{h}^{-1}\end{array}$ & $\begin{array}{c}\text { No-tillage } \\
\text { planter }\end{array}$ & $\begin{array}{c}\text { Mean of } \\
\text { samples/cm }\end{array}$ & $\begin{array}{c}\text { Standard deviation of } \\
\text { samples }\end{array}$ & $\begin{array}{c}\text { Variation } \\
\text { coefficient/\% }\end{array}$ \\
\hline \multirow{2}{*}{5} & 2BM-4 & 23.2 & 5.57 & 24.01 \\
& 2BM-4A & 21.2 & 1.98 & 9.34 \\
\hline \multirow{2}{*}{8} & 2BM-4 & 23.6 & 6.09 & 25.81 \\
& 2BM-4A & 22.0 & 2.11 & 9.59 \\
\hline
\end{tabular}

\section{Conclusions}

(1) The direct drive of seeding and fertilizing parts by the ground wheel was replaced by a friction wheel transmission, which largely improved the transmission reliability of no-tillage planters under the condition of abundant ground mulching.

(2) Through theoretically analysis of the relationship between tyre pressure and tyre deformation, the calculated transmission resisting moment is $122 \mathrm{~N} \cdot \mathrm{m}$ and pressing force on the friction wheel $(13 \times 5.00-6$ tyre $)$ is
$14 \mathrm{kN}$, the theoretical minimum tire deformation for ensuring transmission is $8.7 \mathrm{~mm}$.

(3) Field tests proved that the best effect of the friction wheel transmission or namely the highest stability can be obtained at the friction wheel tire pressure of 24.345 psi $(167.589 \mathrm{kPa})$. The transmission of friction wheel can reduce $14.67 \%$ in variation coefficient of seed spacing at the speed of $5 \mathrm{~km} / \mathrm{h}$ and $16.22 \%$ at the speed of $8 \mathrm{~km} / \mathrm{h}$.

\section{Acknowledgements}

We acknowledge that the research was financially supported by the 13th Five-Year Plan for National Science and Technology (Grant No.2016YFD0700302, 20140309001NY), Science and Technology Project of Jilin Provincial Education Department (JJKH20170811KJ), Science and Technology Development Project of Jilin Province (20160307011NY).

\section{[References]}

[1] Rajaiah P, Mani I, Kumar A, Singh A K. Role of physical and engineering properties of rice (Oryza sativa) cultivars for designing of precision planter. The Indian Journal of Agricultural Sciences, 2015; 85(12).

[2] Sharipov G M, Paraforos D S, Pulatov A S, Griepentroga H W. Dynamic performance of a no-till seeding assembly. Biosystems Engineering, 2017; 158: 64-75.

[3] Chen Y J, Yi X Y, Fang L N, Li Q Q. Analysis for arable land resources and its grain production capacity in China. Chinese Journal of Agricultural Resources and Regional Planning, 2012; 33(6): 4-10. (in Chinese)

[4] Cui H S, Zhang B, Yu L, Zhu J H, He Y F. Pattern and change of black soil resources in China. Resources Science, 2003; 25(3): 64-68. (in Chinese)

[5] Rathinakumari C, Jesudas D M. Design and development of tractor operated onion set planter. The Indian Journal of Agricultural Sciences, 2015; 85(8).

[6] Zhao J L, Huang D Y, Jia H L, Zhuang J, Guo M Z. Analysis and experiment on cutting performances of high-stubble maize stalks. Int J Agric \& Biol Eng, 2017; 10(1): 40-52.

[7] Jia H L, Zhao J L, Jiang X M, Yuan H. Design and optimization of a double-concave rocker seedmeter for precision seeding. AMA-Agricultural Mechanization in Asia Africa and Latin America, 2015; 46(2): 29-34.

[8] Liu B Y, Yan B X, Shen B, Wang Z Q, Wei X. Current status and comprehensive control strategies of soil erosion for 
cultivated land in the Northeastern black soil area of China. Science of Soil and Water Conservation, 2008; 6(1): 1-8. (in Chinese)

[9] Jia H L, Ma C L, Li H Z, Chen Z L. Tillage soil protection of black soil zone in Northeast of China based on analysis of conservation tillage in the United States. Transactions of the CSAM, 2010; 41(10): 28-34. (in Chinese)

[10] Cai Y L. Problems of farmland conservation in the rapid growth of Chinese economy. Resources Science, 2000; 22(3): 24-28. (in Chinese)

[11] Jia H L, Ma C L, Liu Z C, Yang Q, Li G Y, Liu H. Overview of study on the tillage mode of water storage and soil moisture conservation for dry farming region in Northern China. Transactions of the CSAM, 2007; 38(12): 190-194, 207. (in Chinese)

[12] Zhang R, Cui T, Han D D, Zhang D X, Li K H, Yin X W, et al. Design of depth-control planting unit with single-side gauge wheel for no-till maize precision planter. Int J Agric \& Biol Eng, 2016; 9(6): 56-64.

[13] Yang L, Zhang R, Gao N N, Cui T, Liu Q W, Zhang D X. Performance of no-till corn precision planter equipped with row cleaners. Int J Agric \& Biol Eng, 2015, 8(5): 15-25.

[14] Stefanello G, Machado A L T, Reis V, Machado R L T, de Morais C S. Functional structure of a human-powered seeder. Ciência Rural, 2014; 44(9): 1583-1588.

[15] Khaleghian S, Taheri S. Terrain classification using intelligent tire. Journal of Terramechanics, 2017; 71: 15-24.

[16] Zhang P X, Qiao J Z, Guo L, Li W S. Sliding mode friction observer based control for flexible spacecraft with reaction wheel. IET Control Theory \& Applications, 2016; 11(8): 1274-1281.

[17] Fan H W, Zhao L Q. Mathematical model and experimental research of interaction between elastic tire and soft terrain. Journal of Tsinghua University (Sci \& Tech), 1997; 37(11): 112-116. (in Chinese)

[18] Conradie J M, Els P S, Heyns P S. Finite element modelling of off-road tyres for radial tyre model parameterization. Proceedings of the Institution of Mechanical Engineers Part D: Journal of Automobile Engineering, 2016; 230(4): 564-578.

[19] Cho J R, Lee H W, Jeong W B, Jeong K M, Kim K W. Finite element estimation of hysteretic loss and rolling resistance of 3-D patterned tire. International Journal of Mechanics and Materials in Design, 2013; 9(4): 355-366.
[20] Cueto O G, Coronel C E I, Morfa C A R, Sosa G U, Gómez L H H, Calderón G U, et al. Three dimensional finite element model of soil compaction caused by agricultural tire traffic. Computers and Electronics in Agriculture, 2013; 99: $146-152$

[21] Sun J, Yuan X M. A state-of-art of research on dynamic modulus and damping ratio of soils. World Earthquake Engineering, 2003; 19(1): 88-95. (in Chinese)

[22] Lai Y N, Zhang G Y, Chen Z G. Spacecraft docking rotating simulator based on virtual prototype. Journal of System Simulation, 2005; 17(3): 639-641, 649. (in Chinese)

[23] Zhang Q. Research and application status of agricultural instruments. Agricultural Engineering, 2012; 2(2): 40-45. (in Chinese)

[24] Lv X J, Lu W L, Song Z W, Zhang Y. Study on spatial variability of soil temperature and water in field. Journal of Irrigation and Drainage, 2006; 25(6): 79-81.

[25] Tan D R, Wang Y Y, Zhang L. The research about the method of indirect tire pressure monitoring based on Kalman filter algorithms. Journal of Agricultural Mechanization Research, 2007; 12: 74-78. (in Chinese)

[26] Fu W, Luo X W, Zeng S, Wang Z M, Wang C W, Yuan Q B. Design and experiment of electro-hydraulic proportional control hill distance system of precision rice hill-drop drilling machine for dry land. Transactions of the CSAE, 2015; 31(9): 25-31. (in Chinese)

[27] Garcia R F, Vale W G, de Oliveira M T R, Braga T C. Influence of displacement speed in the performance of a precision no-till planter in northern Rio de Janeiro State. Acta Scientiarum. Agronomy, 2011; 33(3): 417-422.

[28] Frabetti D R, Resende R C, Queiroz D M, Fernandes H C, Solza C M. Development and evaluation performance of a punch planter for direct sowing of corn. Revista Brasileira de Engenharia Agrícola e Ambiental, 2011; 15(2): 199-204.

[29] Hanna H M, Steward B L, Aldinger L. Soil loading effects of planter depth-gauge wheels on early corn growth. Applied Engineering in Agriculture, 2010; 26(4): 551-556.

[30] Vale W G, Garcia R F, Thiebaut J T L, Gravina G A. Statistical characterization of variables used to test a planter under direct and conventional sowing systems. Acta Scientiarum. Agronomy, 2009; 31(4): 559-567.

[31] Bakhtiari M R, Loghavi M. Development and evaluation of an innovative garlic clove precision planter. Journal of Agricultural Science and Technology, 2010; 11: 125-136. 